\title{
Cystic fibrosis-gastritis-megaloblastic anemia syndrome
}

INSERM

\section{Source}

INSERM. (1999). Orphanet: an online rare disease and orphan drug data base. Cystic fibrosis-gastritis-megaloblastic anemia syndrome. ORPHA:2575

Cystic fibrosis-gastritis-megaloblastic anemia, or Lubani-AI Saleh-T eebi syndrome, is a rare genetic disease reported in two siblings of consanguineous Arab parents and is characterized by cystic fibrosis, gastritis associated with Helicobacter pylori, folate deficiency megaloblastic anemia, and intellectual disability. There have been no further descriptions in the literature since 1991. 